\title{
Exploring and Modeling the Chemical Effect of a Cetane Booster Additive in a Low- Octane Gasoline fuel
}

\author{
Minh Duy Le, Mickael Matrat, and Arij Ben Amara IFP Energies Nouvelles \\ Fabrice Foucher, Bruno Moreau, and Yi Yu PRISME, Université d'Orléans \\ Pierre-Alexandre Glaude LRGP, CNRS-Université de Lorraine
}

\begin{abstract}
Recent internal combustion (IC) engine developments focus on gasoline fuel. This requires a better understanding of fuel reactivity at different thermodynamic conditions. Gasoline fuel reactivity control by additives is an efficient method to get better IC engine performances. 2-Ethylhexyl nitrate (EHN) promoting effect $(0.1-1 \%$ mol.) on combustion has been investigated experimentally and numerically. Rapid compression machine (RCM) experiments were carried out at equivalence ratio 0.5 at $10 \mathrm{bar}$, from 675 to $995 \mathrm{~K}$. The targeted surrogate fuel is a mixture of toluene and $n$-heptane in order to capture the additive effect on both cool flame and main ignition. A kinetic model was developed from literature data assembly and validated upon a large set of variations including species profiles and ignition delays of pure compounds as well as mixtures. At the experimental conditions, it was found that the EHN reduces the ignition delay time (IDT) of the surrogate fuel in the whole temperature range. EHN effectiveness tends to be minimum around $705 \mathrm{~K}$ and increases with temperature. The results also indicate that EHN effect increases nonlinearly with EHN doping levels. Numerical analyses revealed that the EHN effect is linked to $\mathrm{NO}_{2}-\mathrm{NO}$ loops, which enhances fuel reactivity. The methodology proposed here enable to simulate the EHN effect with simple compounds rather than the full EHN chemistry set. This strategy could simplify the consideration of additive effect when computational fluid dynamics (CFD) simulations are performed on engine. Finally, the study also highlights the EHN effectiveness on several thermodynamic conditions as well as equivalence ratios. The objective is to assess its performance upon large operating conditions which appears to be of interest with novel combustion systems targeting low temperature as well as lean combustion.
\end{abstract}

\section{Introduction}

Worldwide transport is actually powered nearly entirely by IC engines. Their contribution in this sector is expected to be still very high in the next few decades. Novel combustion systems, such as spark assisted compression ignition (SACI) [1] or gasoline compression ignition (GCI) [2] are being developed for better performances. These combustion systems aim at increasing the engine efficiency. Their operation in lean combustion is a lever to reach this objective. This combustion mode operates in low temperature, which can result in low nitrogen oxides $\left(\mathrm{NO}_{\mathrm{x}}\right)$ and soot emissions. The main disadvantages of lean combustion are over-frequent misfire and engine instability [3]. In addition, the novel combustion systems currently investigated tend to explore new thermodynamic conditions for the combustion of gasoline fuels. Thus, reactivity control is one of the most difficult challenges regarding these engine developments. This task requires both experimental and simulations results. CFD simulations are a reliable method of engine simulation [4]. This kind of simulations require a simple but robust kinetic model to reduce computational cost.
To replace fossil fuels, renewable energy sources such as biofuel or natural gas have been studied and used in different kind of engines [5, 6]. In the near future, taking advantage of all petroleum fractions is one of the most efficient way in using petroleum fuels. In this scope, low octane gasoline fuel is of interest. The benefits of this kind of fuel link to its low cost thanks to simple treatment in petroleum refineries. This fuel can be used in many moderns IC engines presented previously such as SACI or GCI.

Fuel additives have been used to control the fuel reactivity in many types of engines [7, 8]. EHN is a conventional additive used to enhance the reactivity of diesel fuels. The EHN efficiency has been investigated in many types of engines operating at low temperature $[9,10]$. Ghosh et al. [11], by carrying out cetane number $(\mathrm{CN})$ measurements in ignition quality tester (IQT), observed that EHN effectiveness in $\mathrm{CN}$ boosting increases with the base fuel reactivity. In order to fundamentally understand EHN effect, previous academic studies investigated the EHN effect on the autoignition of gasoline fuels having a different reactivity $[12,13]$. These studies underline a complex promoting effect of EHN that depends on the thermodynamic conditions, the doping level and the fuel chemical composition. Since EHN decomposes to an alkoxy radical and $\mathrm{NO}_{2}$ at relatively low temperature [14], the chemical effect of EHN depends on both the derived radicals and the nitrogen chemistry. Hartmann et al. [12] and Goldsborough et al. [13] developed kinetic models to predict EHN behavior in mixture with $n$-heptane and two reference fuels ( $n$-heptane/ iso-octane/ toluene mixtures) respectively. These modeling works reveal that two mains items need to be improved: (1) the prediction of the base fuel reactivity and (2) the coupling of nitrogen chemistry with hydrocarbons. Indeed, a confident prediction of base fuel reactivity is an important step to ensure a better investigation of EHN effect. Moreover, detailed mechanisms regarding nitrogen chemistry interactions with large hydrocarbons still need to be explored, especially for lean mixtures.

In order to assess the effect of a nitrogen containing additive under different conditions, this study aims at: (1) investigating experimentally and numerically the EHN effect at typical dopant amounts $(0.1-1 \%$ mol.) on the autoignition behavior of a low-octane gasoline surrogate fuel in lean combustion; (2) understanding the chemical effect of EHN on the fuel reactivity at different thermodynamic conditions and (3) investigating numerically EHN effect in various fuels, whose reactivity are different depending on the operating conditions. The employed fuel surrogate in experiments is a mixture of $n$-heptane and toluene with a research octane number (RON) of 84 which falls into a low octane gasoline range. The mixture also offers the possibility to evaluate both the additive effect on high temperature and low temperature with two stage ignitions due to a nonnegligible amount of alkane. In this study, IDT were measured in a RCM and a detailed kinetic mechanism containing nitrogen chemistry for fuel/EHN mixture was developed thanks to the assembly of literature data. 


\section{Experiments}

The single piston RCM of PRISME laboratory was used in this study. The details of this RCM can be found elsewhere [15]. A creviced piston was employed to limit the formation of a roll-up vortex during the compression and maintain the post-compression charge homogeneity. The main characteristics of the RCM of PRISME laboratory are summarized in the table 1.

Table 1. RCM main characteristics.

\begin{tabular}{|l|l|}
\hline Compression time & $35 \mathrm{~ms}$ \\
\hline Time $\mathrm{P}_{\max } / 2$ to $\mathrm{P}_{\max }\left(\mathrm{t}_{50}\right)$ & $4 \mathrm{~ms}$ \\
\hline Piston acceleration/deceleration time & $15 / 5 \mathrm{~ms}$ \\
\hline Crevice volume & $9.94 \mathrm{~cm}^{3}$ \\
\hline Compression ratio & $8.9 ; 12.9 ; 20.7$ \\
\hline Stroke, bore & $300 \mathrm{~mm}, 50 \mathrm{~mm}$ \\
\hline
\end{tabular}

The intake pressure was measured by a Keller PAA-33X/80794 piezoresistive transducer. The in-cylinder pressure history was registered thanks to a piezoresistive AVL QH32C transducer. The temperatures including intake temperature and piston initial temperature were controlled by $\mathrm{K}$ thermocouples. The Brooks CoriFlows M13V101 were used to regulate the mass flow rates. The experimental uncertainties of intake pressure, in-cylinder pressure, intake temperatures and mass flowrate are \pm 1 mbar, $\pm 1 \%, \pm 2 \mathrm{~K}, \pm 1 \%$, respectively.

The high purity liquid fuels used in this study are from Sigma-Aldrich: toluene (99.8\%), $n$-heptane (99\%), EHN (97\%). To fulfill the desired gas mixture, the synthetic air $\left(21 \% \mathrm{O}_{2}, 79 \% \mathrm{~N}_{2}\right)$ and high purity nitrogen (> 99.999\%) from Air Liquide are used. The base fuel contains toluene $(65 \%$ vol.) and $n$-heptane ( $35 \%$ vol.). These components present different reactivity in the low temperature range $(\mathrm{T}<1000 \mathrm{~K})$ and were also used as fuel surrogate in literature due to the adequate comprehension of their chemistry. The doping level of $\mathrm{EHN}$ in the base fuel varies from 0.1 (mixture 2) to $1 \%$ mol. (mixture 3 ). The composition of gas mixtures used in this study is shown in table 2 .

Table 2. Mole fraction of the different gas mixtures in RCM experiments.

\begin{tabular}{|c|c|c|c|c|c|}
\hline Mix. & Toluene (\%) & $n$-Heptane $(\%)$ & EHN $(\mathrm{ppm})$ & $\mathrm{O}_{2}(\%)$ & $\mathrm{N}_{2}(\%)$ \\
\hline 1 & 0.78 & 0.31 & 0 & 20.77 & 78.14 \\
\hline 2 & 0.78 & 0.31 & 10.86 & 20.77 & 78.14 \\
\hline 3 & 0.77 & 0.3 & 108.61 & 20.77 & 78.14 \\
\hline
\end{tabular}

The pressure at top dead center $\left(\mathrm{P}_{\mathrm{c}}=10 \mathrm{bar}\right)$ and temperatures at top dead center $\left(\mathrm{T}_{\mathrm{c}}\right)$ are achieved by adjusting the initial temperature $\left(\mathrm{T}_{0}\right)$, from 55 to $120^{\circ} \mathrm{C}$, and the intake pressure $\left(\mathrm{P}_{0}\right)$, from 227 to 600 mbar. $\mathrm{T}_{\mathrm{c}}$ are calculated by using the adiabatic core model. The gas mixtures were prepared in a reservoir on the day of manipulation. The reservoir was heated to $80^{\circ} \mathrm{C}$ to ensure the total vaporization of the fuel. The homogeneity of each gas mixture was ensured by a mechanic agitation during 30 minutes.

As presented in figure 1, the main IDT is defined as the time between the end of the compression and the combustion Maximum Pressure Rise Rate (MPRR), which is the maximum value of $d P / d t$ calculations. In the case of two-stage ignition, the $1^{\text {st }}$-stage IDT is defined as the time between the end of compression and the first distinguishable peak of $d P / d t$ calculations. The measurable IDT by this RCM ranges from 1 to $200 \mathrm{~ms}$.

Page 2 of 8

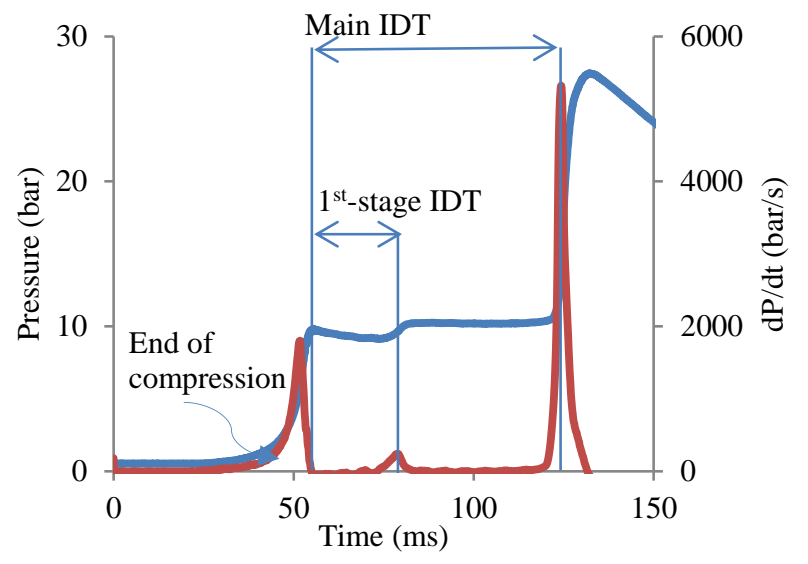

Figure 1. Typical pressure (blue line) and $d P / d t$ (red line) profiles in RCM experiment. Experimental condition: surrogate fuel, $\Phi=0.5,705 \mathrm{~K}, 10$ bar.

\section{Kinetic Modeling}

A kinetic model was developed to simulate the EHN effect on the fuel surrogate. This model contains three sub-mechanisms describing chemistry of the base fuel, of EHN and of nitrogenous molecules. The sub-mechanism of the base fuel was adopted from the model of Lawrence Livermore National Laboratory (LLNL) [16], which contains detailed chemistry of toluene and $n$-heptane. The toluene submechanism was then updated following mostly the recent study of aromatic molecules by Yuan et al. [17]. The updated reactions include the elementary reactions of toluene and its derived radicals and molecules, e.g., phenyl, benzyl, methylphenyl, cresoxy radicals, phenol, cresol and small unsaturated compounds $\mathrm{C}_{2}-\mathrm{C}_{4}$. The importance of 1,3-cyclopentadiene $\left(\mathrm{C}_{5} \mathrm{H}_{6}\right)$ and cyclopentadienyl radical $\left(\mathrm{C}_{5} \mathrm{H}_{5}\right)$ chemistry toward the toluene reactivity is highlighted by Yuan et al. [17]. Therefore, $\mathrm{C}_{5} \mathrm{H}_{6}$ sub-mechanism was updated according to recent data [18-20].

Concerning the reaction pathway of EHN, previous studies agree on the main decomposition steps $[12,13,21]$. First, the weakest bond $(\mathrm{O}-$ $\mathrm{N}$ bond) of EHN molecule is broken to release $\mathrm{NO}_{2}$. The 2ethylhexyloxy (EHO) radical can then undergo a $\beta$-scission to form formaldehyde and 3-heptyl radical. This reaction pathway of EHN is adopted in this study. As EHN releases $\mathrm{NO}_{2}$ during its decomposition, nitrogen chemistry and its interactions with hydrocarbons are included in this kinetic model. $\mathrm{NO}_{\mathrm{x}}$ sub-mechanism containing small molecules $\left(\mathrm{C}_{1}-\mathrm{C}_{2}\right)$ was adopted mainly from the recent review of Glarborg et al. [22]. The reactions of nitroethane proposed by Zhang et al. [23] were included in the model. The same reaction scheme was adapted to describe the reactivity of the two nitropropane isomers (1-nitropropane and 2-nitropropane). The $\mathrm{NO}_{\mathrm{x}}$ interactions with heavier hydrocarbons $\left(\mathrm{C}_{4}-\mathrm{C}_{7}\right)$ were based on the work of Anderlorh et al. [24] and Chai et al. [25].

The validation of the kinetic model was carried out using both literature [26-31] and measurements performed in this work. The target data include IDT and species profiles measurements. Experimental conditions cover a wide range of temperature and pressure (500 - $1200 \mathrm{~K}, 1-50 \mathrm{bar}$ ) as well as reactor types (shock tube, plug flow reactor and perfectly stirred reactor). This step validates the mechanism for the combustion of mixtures of toluene and $n$-heptane as well as for interactions between $\mathrm{NO}_{\mathrm{x}}$ and hydrocarbons.

In this study, the RCM results are simulated by using the 0 -D closed homogenous reactor model in CHEMKIN-PRO [32]. During compression process, a frozen chemistry assumption is employed. 
This assumption could be justified by the low reactivity of the surrogate fuel in the investigated experimental conditions. The heat loss during the combustion is taken into account by using an "effective volume", which is calculated by adopting the adiabatic core hypothesis. To obtain the volume profiles, non-reactive experiments with $\mathrm{N}_{2}$ were first performed at the same initial pressure and temperature as for each of the targeted experiment.

\section{Results and Discussions}

The experimental and modeling results are presented as follows. First, the measured and simulated IDT of the base fuel with/without EHN in RCM experiments are introduced. Then the EHN effect on the reactivity of the base fuel is chemically discussed thanks to the kinetic model. Finally, the impact of fuel reactivity, pressure and equivalence ratio on EHN efficiency are numerically investigated.

\section{RCM Experiments Results and Simulations}

Figure 2 presents the experimental results obtained in this study and the simulations of the $1^{\text {st }}$-stage and main IDT of the surrogate fuel with and without addition of EHN. The measurements were conducted at 10 bar from 675 to $1000 \mathrm{~K}$ for an equivalence ratio $(\Phi)$ of 0.5 . A twostage ignition is observed at the lowest temperatures $(\mathrm{T}<750 \mathrm{~K})$. This feature is reasonably captured by the model.

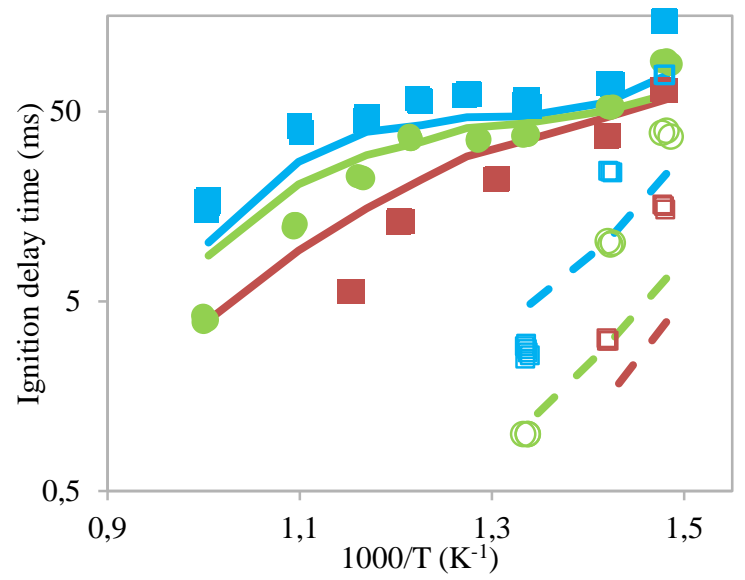

Figure 2. Effect of EHN for two dopant concentrations: $0.1 \%$ (green) and 1\% (red), on the reactivity of the surrogate fuel (blue) at 10 bar and $\Phi=0.5$. Experiments: symbol. Simulation: line. Main IDT: solid lines and filled

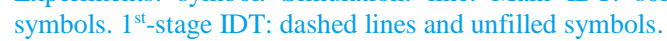

Globally, the kinetic model predicts correctly the surrogate fuel reactivity. The most remarkable differences between experimental and modeling results are observed at low temperatures $(\mathrm{T}<700 \mathrm{~K})$, for which the model underestimates the IDT of the fuel. The considered 0D simulation method in this study could be used to model reliably the RCM results for single-stage ignition fuel [13]. However, due to the complex multi-dimensional effects inside RCM initiated by boundary layer, roll-up vortex, non-uniform heat release and piston crevice, the multi-stage ignition processes are highly perturbed. The measured IDT can be increased up to $25 \%$ [33]. The application of 0-D simulation method is consequently under debate for multi-stage ignition fuels [33]. A computational fluid dynamics (CFD) simulation as presented by Mittal et al. [33] could be used to get a better agreement between experiments and simulations when a two-stage ignition is observed however this is beyond the scope of the study. In addition, most of toluene reactions in this model are adopted from the model by Yuan et al. [17]. However, there is a large spread in predictions of IDT of toluene at low temperature $(\mathrm{T}<873 \mathrm{~K}$ ) by recent models in the literature, including Yuan et al.'s model, as it has been observed by Zhang et al. [34]. In fact, due to the low reactivity of toluene and to experimental device limitations, the available data for validation at low temperature are limited. Further studies would be required in order to get more reliable simulation results.

As presented in figure 2 , at 10 bar and $\Phi$ of 0.5 , EHN shows a promoting effect at all investigated temperatures for both $1^{\text {st }}$-stage and main ignition of the surrogate fuel. At doping level of $1 \%$ mol., EHN suppresses the cool flame of the surrogate fuel ignition at $750 \mathrm{~K}$. This feature is captured by the model. When two-stage ignitions are observed, the time between $1^{\text {st }}$-stage ignition and the main ignition is not affected by EHN. It can be concluded that EHN shows its effect only on the $1^{\text {st }}$-stage IDT of the two-stage ignition. The EHN promoting effect increases nonlinearly with EHN doping levels. For a given doping level, EHN shows the smallest effect around $705 \mathrm{~K}$. EHN reduces more significantly IDTs of the surrogate fuel as temperature increases. The model underestimates slightly EHN effect at the upper range of temperature $(\mathrm{T}>850 \mathrm{~K}$ ). Overall, the model successfully predicts the EHN effect on the IDT of the surrogate fuel over the whole range of examined temperatures and doping levels.

In addition to IDT, the model simulates reasonably well the pressure profiles of RCM experiments. Figure 3 introduces the measured and simulated pressure profiles of measurements with and without EHN $0.1 \%$ at $705 \mathrm{~K}, 10$ bar and $\Phi$ of 0.5 . The heat release governs directly the pressure profile. Experimental results indicate that EHN does not influence the heat release magnitude of the $1^{\text {st }}$-stage ignition. This feature is well predicted by the kinetic model developed in this study. In all conditions, the model predicts reliably the peak pressure of the $1^{\text {st }}$-stage ignition. Additionally, the simulated peak pressures of main ignition are about 4 bar in average higher than the measured ones. This fact could be associated to the heat loss of combustion to the piston, to the mass loss of the fuel during the experiment preparation, which is estimated about $3 \%$ of initial fuel mass and to the uncertainty of pressure transducer $( \pm 1 \%)$.

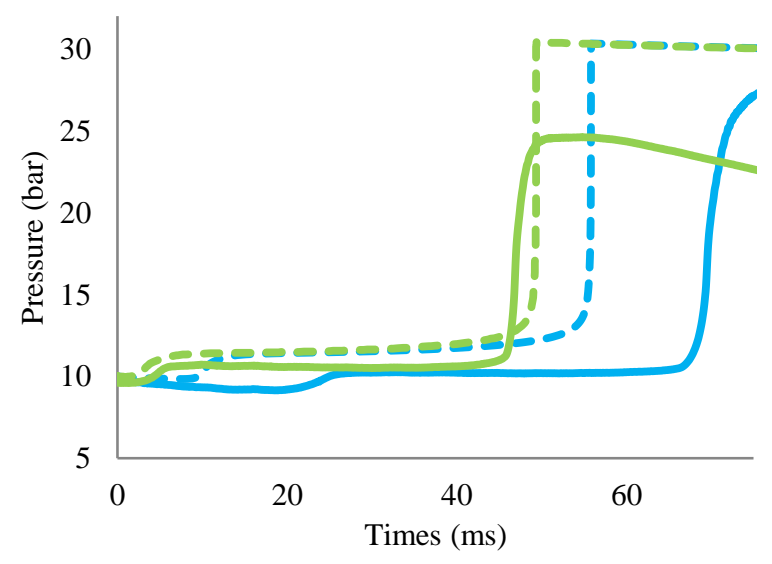

Figure 3. Measured (solid lines) and simulated (dashed lines) pressures profiles in the RCM at 10 bar, $705 \mathrm{~K}$ and $\Phi=0.5$. Undoped surrogate fuel: blue, surrogate fuel with $0.1 \% \mathrm{EHN}$ : green.

RCM data validation step confirms the good performance of the new kinetic model, which predicts reliably the EHN effect on the reactivity of the surrogate fuel in lean combustion.

Page 3 of 8 


\section{EHN Effect Evaluation via Kinetic Modelling}

The simulation results indicate that EHN decomposes totally within less than $1 \mathrm{~ms}$ for initial concentrations at all considered temperatures (675 - $995 \mathrm{~K})$ in RCM experiments. EHN influences the reactivity at a very early time. The products of EHN decomposition are EHO and $\mathrm{NO}_{2}$. An analysis by species substitution is carried out to investigate the importance of each product. In this analysis, a reactive compound is replaced by a non-reactive one called "fictive compound" having the same thermodynamic properties. For example, to determine $\mathrm{NO}_{2}$ effect formed by the reaction $\mathrm{EHN}=\mathrm{EHO}+\mathrm{NO}_{2}, \mathrm{NO}_{2}$ in this reaction is replaced by a non-reactive molecule " $\mathrm{NO}_{2}$-fictive". The simulated IDT in presence of $\mathrm{NO}_{2}$-fictive is IDT $\mathrm{NO}_{2}$. A new parameter named Impact Ratio $\left(\mathrm{IR}_{\mathrm{N}}\right)$, with $\mathrm{N}$ being the compound replaced by the corresponding fictive compound, is defined as:

$$
I R_{N}=\frac{I D T_{N}-I D T_{\text {normal }}}{I D T_{\text {normal }}} \times 100 \%
$$

IDT $_{\text {normal }}$ is the simulated IDT without any fictive compound. IR $_{\mathrm{N}}$ can take negative or positive value. If $\mathrm{IR}_{\mathrm{N}}$ is positive, the compound $\mathrm{N}$ has a promoting effect for the fuel reactivity and vice versa, the compound $\mathrm{N}$ has an inhibitor effect if $\mathrm{IR}_{\mathrm{N}}$ is negative. Bigger the absolute value of $\mathrm{IR}_{\mathrm{N}}$ is, the corresponding compound $\mathrm{N}$ has higher impact on the reactivity of the fuel.

Figure 4 presents the impact ratios of $\mathrm{EHO}$ and $\mathrm{NO}_{2}$ for $\mathrm{EHN}$ effect considering the RCM experimental conditions investigated in this study. While $\mathrm{IR}_{\mathrm{NO} 2}$ varies with temperature, $\mathrm{IR}_{\mathrm{EHO}}$ is nearly constant. The absolute value of IR $\mathrm{NO}_{2}$ is generally larger than the one of IReHO. It can be concluded that $\mathrm{NO}_{2}$ conducts globally the EHN effect in the considered experimental conditions especially at doping level of $1 \%$ in the upper range of temperature $(\mathrm{T}>850 \mathrm{~K})$. Additionally, $\mathrm{NO}_{2}$ has a very small inhibiting effect on the surrogate fuel reactivity at very low temperature $(\mathrm{T}<700 \mathrm{~K})$.

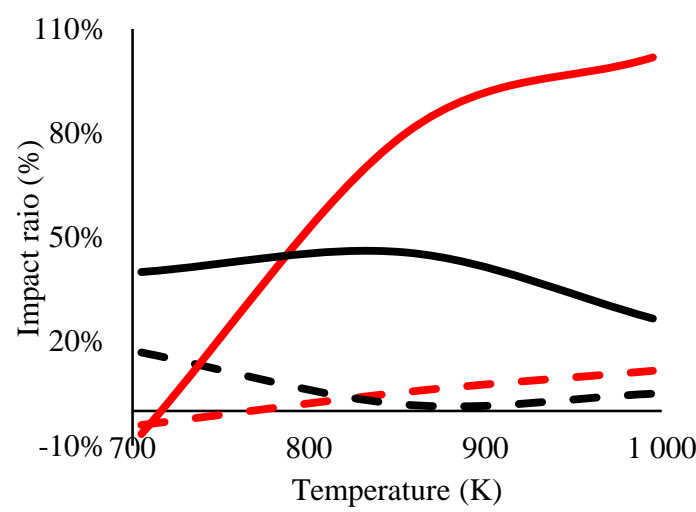

Figure 4. Impact ratios of EHO (black) and $\mathrm{NO}_{2}$ (red) in EHN effect at two doping levels: $0.1 \%$ mol. (dashed lines) and $1 \%$ mol. (solid lines) for the surrogate fuel reactivity. Experimental conditions: $\Phi=0.5,10$ bar.

One application of kinetic model is to be used in CFD simulation to get reliable engine simulation results. In order to reduce the computational cost, the kinetic model is required to be as simple as possible. Therefore, it is important to investigate whether EHN could be replaced by a simpler molecule. The results presented figure 4 suggest that only $\mathrm{NO}_{2}$ could be used to replace EHN in simulation especially at temperature above $850 \mathrm{~K}$. This feature is presented in figure 5. $\mathrm{NO}_{2}$ promoting effect is generally similar to $\mathrm{EHN}$ promoting effect. The simulated IDT in the presence of $\mathrm{NO}_{2}$ is about $30 \%$ higher than the one in the presence of EHN at the same doping level (1\% mol.).

Page 4 of 8

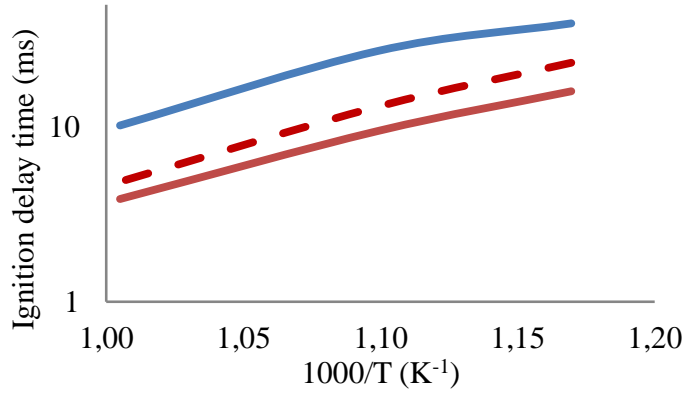

Figure 5. Simulated IDT of the surrogate fuel in this study in presence of additives. Conditions simulations: $\Phi=0.5,10$ bar. Neat surrogate: blue solid line. Surrogate with EHN (1\% mol.): red solid line. Surrogate with $\mathrm{NO}_{2}(1 \%$ mol.): red dashed line.

In RCM experiments of this study, it is found that EHN promoting effect reaches a minimum around $705 \mathrm{~K}$ and increases with temperature. To understand this trend, rate of production (ROP) analyses at $1 \mathrm{~ms}$ are carried out for different EHN doping levels (0, 0.1 and $1 \%$ mol.). The simulation conditions are: $10 \mathrm{bar}, \Phi=0.5$ and two temperatures: $705 \mathrm{~K}$ and $995 \mathrm{~K}$.

At $705 \mathrm{~K}, \mathrm{EHN}$ effect depends more on $\mathrm{EHO}$, which decomposes to form an isomer of $n$-heptyl radical $\left(\mathrm{C}_{7} \mathrm{H}_{15}-3\right)$. This $n$-heptyl radical contributes to the $n$-heptane oxidation as presented in figure 6 . This feature enhances the reactivity of the surrogate fuel.

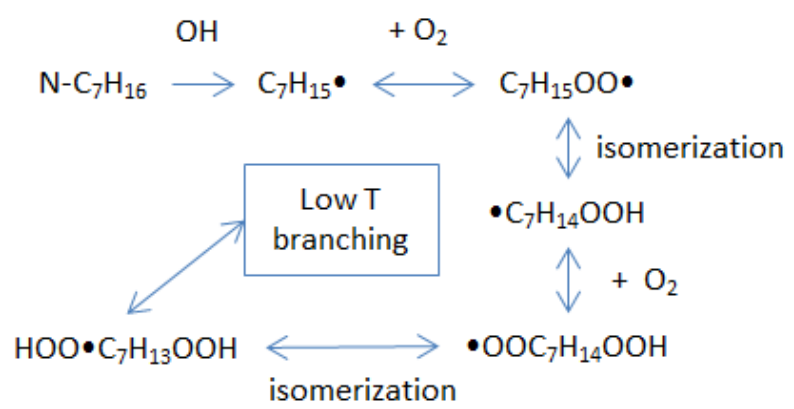

Figure 6. Main oxidation pathway of $n$-heptane at $705 \mathrm{~K}$.

In addition to $\mathrm{EHO}, \mathrm{NO}_{2}$ can contribute to promote the surrogate fuel reactivity by enhancing toluene oxidation. Figure 7 represents the schematic oxidation of toluene at $705 \mathrm{~K}$ :

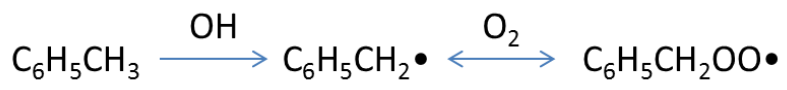

Figure 7. Main oxidation pathway of toluene at $705 \mathrm{~K}$.

At $705 \mathrm{~K}$, toluene forms principally benzyl radical by $\mathrm{H}$-abstraction reaction. This radical then reacts with $\mathrm{O}_{2}$ to form benzyl peroxy radical $\left(\mathrm{C}_{6} \mathrm{H}_{5} \mathrm{CH}_{2} \mathrm{OO}\right)$, which is has a low reactivity due to the limitation of intramolecular isomerization. EHN enhances the reactivity by a loop $\mathrm{NO}_{2}$-NO-(1) as:

$$
\begin{aligned}
& \mathrm{EHN}=\mathrm{EHO}+\mathrm{NO}_{2} \\
& \mathrm{C}_{6} \mathrm{H}_{5} \mathrm{CH}_{2}+\mathrm{NO}_{2}=\mathrm{C}_{6} \mathrm{H}_{5} \mathrm{CH}_{2} \mathrm{O}+\mathrm{NO} \\
& \mathrm{NO}+\mathrm{HO}_{2}=\mathrm{NO}_{2}+\mathrm{OH}
\end{aligned}
$$


The new reaction (R2) leads to the formation of $\mathrm{C}_{6} \mathrm{H}_{5} \mathrm{CH}_{2} \mathrm{O}$ radical, which is more reactive than $\mathrm{C}_{6} \mathrm{H}_{5} \mathrm{CH}_{2} \mathrm{OO} . \mathrm{C}_{6} \mathrm{H}_{5} \mathrm{CH}_{2} \mathrm{O}$ radical can easily break into $\mathrm{C}_{6} \mathrm{H}_{5}$ and $\mathrm{CO}$ by many $\mathrm{H}$ atom release steps. Additionally, reaction $\mathrm{R} 3$ forms $\mathrm{OH}$ radicals. These features enhance the consumption of toluene within the fuel.

At $995 \mathrm{~K}, \mathrm{EHN}$ effect depends importantly on $\mathrm{NO}_{2}$ which has a high impact on toluene oxidation. The schematic oxidation of toluene is presented in figure 8 .

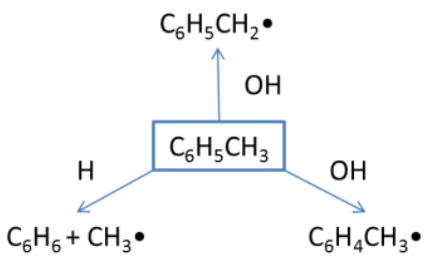

Figure 8. Main oxidation pathway of toluene at $995 \mathrm{~K}$.

At high temperature, toluene reacts with $\mathrm{OH}$ to form both benzyl radical and methylphenyl radical. Additionally, toluene can form benzene and methyl radical by reacting with $\mathrm{H}$ radical. Methyl radical can react with $\mathrm{NO}_{2}$ by a similar way as benzyl radical. As temperature increases, the reaction between $\mathrm{HO}_{2}$ and $\mathrm{NO}_{\mathrm{x}}$ is favored. The loop $\mathrm{NO}_{2}$-NO-(2) representing EHN promoting effect becomes:

$$
\begin{aligned}
& \mathrm{EHN}=\mathrm{EHO}+\mathrm{NO}_{2} \\
& \mathrm{C}_{6} \mathrm{H}_{5} \mathrm{CH}_{2}+\mathrm{NO}_{2}=\mathrm{C}_{6} \mathrm{H}_{5} \mathrm{CH}_{2} \mathrm{O}+\mathrm{NO} \\
& \mathrm{CH}_{3}+\mathrm{NO}_{2}=\mathrm{CH}_{3} \mathrm{O}+\mathrm{NO} \\
& \mathrm{HO}_{2}+\mathrm{NO}_{2}=\mathrm{HONO}+\mathrm{O}_{2} \\
& \mathrm{HONO}=\mathrm{NO}+\mathrm{OH} \\
& \mathrm{NO}+\mathrm{HO}_{2}=\mathrm{NO}_{2}+\mathrm{OH}
\end{aligned}
$$

Compared to the loop $\mathrm{NO}_{2}-\mathrm{NO}-(1)$, the loop $\mathrm{NO}_{2}-\mathrm{NO}-(2)$ generates more $\mathrm{OH}$ radical thanks to the reactions $\left(\mathrm{R}^{*}\right),\left(\mathrm{R}^{* *}\right)$ and $\left(\mathrm{R}^{* * *}\right)$. Consequently, EHN is more efficient at high temperature $(995 \mathrm{~K})$ than at low temperature $(775 \mathrm{~K})$. This trend is well observed in RCM experiments. These ROP analysis results reveal the importance of nitrogen chemistry in EHN promoting effect. It is also observed that EHN effect takes part in the initiation and propagation steps of combustion.

\section{Evaluation of EHN Effect for Several Operating Conditions}

The validated kinetic model is used to investigate numerically EHN effect in various conditions. As presented in figure 2, the best agreement between experiments and simulations is obtained in the range of temperature from 700 to $850 \mathrm{~K}$. The EHN effect prediction focuses in this range of temperature. The 0-D simulations in this part are carried out by using the closed homogenous reactor having a constant volume in CHEMKIN-PRO [32]. The EHN effectiveness $\left(R_{\text {eff }}\right)$ is defined as shown in the equation (1). Higher $R_{\text {eff }}$ is, more effective is EHN in reducing IDT.

$$
R_{\text {eff }}=\frac{I D T_{\text {undoped }}-I D T_{\text {doped }}}{I D T_{\text {undoped }}} \times 100 \%
$$

\section{Variation of RON}

Figure 9 represents EHN effect in various fuels, which are mixtures of toluene and $n$-heptane. The details of these fuels are presented in table 3. RON value of these fuels were measured by Badra et al. [35] in a single-cylinder Cooperative Fuels Research (CFR) engine. The high RON value corresponds to the high reactive fuel and vice versa.

Table 3. Characteristic of fuels used in simulations.

\begin{tabular}{|c|c|c|c|}
\hline \multirow{2}{*}{ Fuel } & \multicolumn{2}{|c|}{ Composition (\% mol.) } & \multirow{2}{*}{ RON } \\
\cline { 2 - 3 } & Toluene & $n$-Heptane & \\
\hline 1 & 0.65 & 0.35 & 84 \\
\hline 2 & 0.50 & 0.50 & 66 \\
\hline 3 & 0.20 & 0.80 & 28 \\
\hline
\end{tabular}

The simulation conditions are: $713 \mathrm{~K}, \Phi=0.7,21.1 \mathrm{~atm}$, which are close to the conditions of IQT tests carried out by Bogin et al. [36]. The simulation results presented in figure 9 indicate that EHN is more effective with more reactive fuel. EHN effectiveness tends to a limit when the doping level increases. These features are coherent with experimental results by IQT test of Ghosh et al. [11]. In fact, the fuel combustion is a series of free radicals reactions consisting of four steps: initiation, propagation, branching and termination [11]. The branching step is the most important step of combustion, which dominates the fuel reactivity. EHN influences the initiation and propagation step of combustion. In the case of low reactive fuel, the branching step is limited and not affected by the presence of EHN. Conversely, the highly reactive fuel takes more advantage of EHN effect: more reactive the fuel is (low RON), more remarkable is the EHN promoting effect.

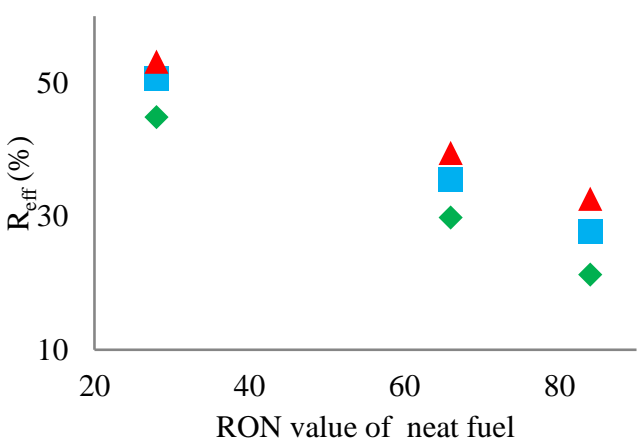

Figure 9. Simulated EHN effectiveness in different fuel with various doping levels: $0.1 \%$ mol. (green), $0.5 \%$ mol. (blue) and $1 \%$ mol. (red). Simulations conditions: $713 \mathrm{~K}, \Phi=0.7,21.1 \mathrm{~atm}$.

\section{Variation of Pressure}

Figure 10 introduces EHN effect (1\% mol.) at different pressures while temperature and mixture composition remain unchanged. Two fuels (RON values of 28 and 84 ) which present very different reactivity were examined. EHN is more effective in the more reactive fuel (RON $=28$ ) at all considered pressures. In addition, EHN effectiveness increases with pressure. While pressure increases, EHN impact is more sensitive to the low reactivity fuel. In the case of low reactivity fuel $(\mathrm{RON}=84)$, as pressure increases from 20 to 30 atm, EHN effectiveness raises from 59 to $68 \%$. Meanwhile, for high reactivity fuel $(\mathrm{RON}=28)$, EHN effectiveness remains nearly constant, from 68 to $71 \%$. 


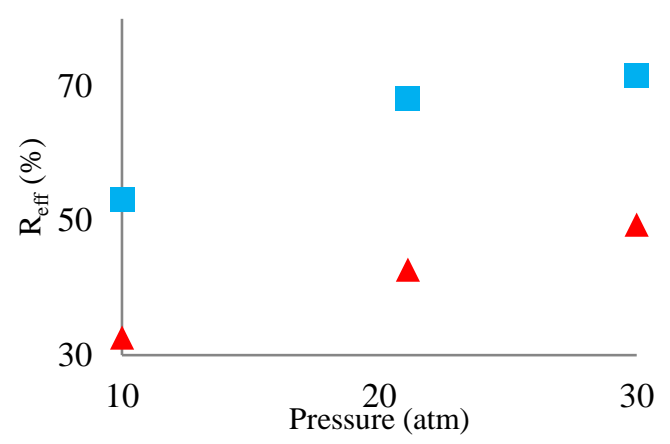

Figure 10. Simulated EHN effectiveness in two fuels having RON of 28 (blue) and RON of 84 (red) with various pressures. Simulations conditions: $713 \mathrm{~K}, \Phi$ $=0.7,1 \%$ mol. EHN.

\section{Variation of Equivalence Ratio}

Figure 11 introduces the influence of EHN in fuel reactivity by varying equivalence ratio. Two fuels having RON values of 28 and 84 were examined. Similarily to the variation of pressure, EHN effectiveness is predicted to increase with equivalence ratio. EHN is always more effective in the more reactive fuel at all equivalence ratios. The EHN influence is more sensitive to equivalence ratio in the case of low reactivity fuel than in the case of high reactivity fuel. For low reactivity fuel $(\mathrm{RON}=84)$, as equivalence ratio increases from 0.7 to 1.3 , EHN effectiveness increases from 43 to $68 \%$. For high reactivity fuel (RON $=28$ ), EHN efficiency changes slightly, from 68 to $78 \%$.

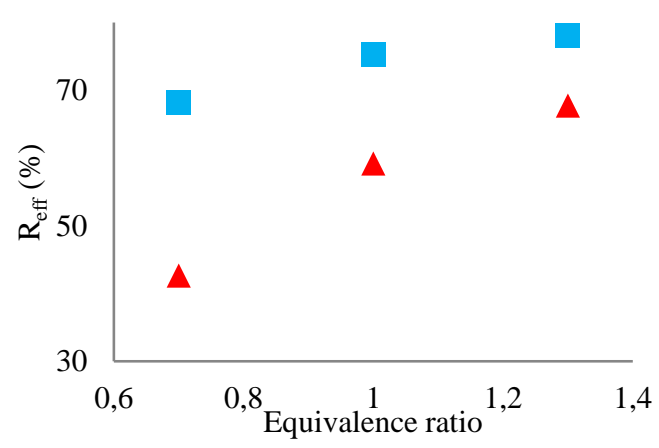

Figure 11. Simulated EHN effectiveness in two fuels having RON of 28 (blue) and RON of 84 (red) with various equivalence ratios. Simulations conditions: $713 \mathrm{~K}, 21.1 \mathrm{~atm}, 1 \%$ mol. EHN.

\section{Conclusions}

In order to evaluate the EHN efficiency on gasoline fuel reactivity control in different conditions, the EHN promoting effect $(0.1-1 \%$ mol.) is investigated experimentally and numerically. RCM experiments were carried out at an equivalence ratio $\Phi$ of 0.5 , a pressure of 10 bar and a temperature range from 675 to $995 \mathrm{~K}$. The targeted fuel is a low-octane gasoline surrogate fuel $(\mathrm{RON}=84)$ comprising both toluene and n-heptane. A kinetic model is developed from literature data assembly. Three sub-mechanisms describing chemistry of the base fuel, of EHN and of nitrogenous molecules are included in the model. The validated kinetic model is used to predict EHN effect in various conditions.

Experiments results indicate that EHN reduces the IDT of the surrogate fuel at all examined temperatures and doping levels. At $750 \mathrm{~K}$, EHN suppresses the cool flame ignition of the surrogate fuel. The EHN effectiveness tends to a minimum around $705 \mathrm{~K}$ and increases with

Page 6 of 8 temperature. The results also indicate that EHN effect increases nonlinearly with EHN doping levels.

The model reasonably predicts the EHN effect over the whole range of examined temperatures and doping levels. Numerical analyses indicate that EHN is effective in the very early stage of combustion thanks to a rapid decomposition. EHN effect depends majorly on $\mathrm{NO}_{2}$ generated by its decomposition, i.e., on nitrogen chemistry. EHN promoting effect is linked to $\mathrm{NO}_{2}$-NO loops, which are temperature dependent. These loops enhance fuel reactivity by forming new pathways of fuel consumption and by giving a supplementary source of $\mathrm{OH}$ radicals, thereby, enhancing the combustion. In order to capture the EHN effect on other kinetic mechanism, this study also demonstrates $\mathrm{NO}_{2}$ addition could be used to simulate most of the doping effect for simulations over a temperature range from 850 to $1000 \mathrm{~K}$.

Simulations by the validated kinetic model in this study indicate that EHN efficiency increases with fuel reactivity, pressure and equivalence ratio.

This study provides insight into the effect of a cetane booster additive (EHN) on the reactivity of fuels. It emphasizes the underlying mechanisms responsible of the reactivity variation at different thermodynamic conditions representative of engine conditions. These results open up the use of kinetic modelling to understand additive kinetics and improve fuel / engine adequacy.

\section{References}

[1] Manofsky, L., Vavra, J., Assanis, D.N., and Babajimopoulos, A., "Bridging the Gap between HCCI and SI: Spark-Assisted Compression Ignition," SAE Technical Paper 2011-01-1179, 2011, doi:10.4271/2011-01-1179.

[2] Kalghatgi, G. and Johansson, B., "Gasoline compression ignition approach to efficient, clean and affordable future engines," Proceedings of the Institution of Mechanical Engineers, Part D: Journal of Automobile Engineering 232(1):118-138, 2017, doi:10.1177/0954407017694275.

[3] Wang, X., Zhang, H., Yao, B., Lei, Y. et al., "Experimental study on factors affecting lean combustion limit of S.I engine fueled with compressed natural gas and hydrogen blends," Energy 38(1):58-65, 2012, doi:10.1016/j.energy.2011.12.042.

[4] Puduppakkam, K., Naik, C.V., Meeks, E., Krenn, C. et al., "Predictive Combustion and Emissions Simulations for a High Performance Diesel Engine Using a Detailed Fuel Combustion Model," SAE Technical Paper 2014-01-2570, 2014, doi: 10.4271/2014-01-2570.

[5] McCormick, R.L., Ratcliff, M.A., Christensen, E., Fouts, L. et al., "Properties of Oxygenates Found in Upgraded Biomass Pyrolysis Oil as Components of Spark and Compression Ignition Engine Fuels," Energy Fuels 29(4):2453-2461, 2015, doi:10.1021/ef502893g.

[6] Ansari, E., Menucci, T., Shahbakhti, M., and Naber, J., "Experimental investigation into effects of high reactive fuel on combustion and emission characteristics of the Diesel - Natural gas Reactivity Controlled Compression Ignition engine," Applied Energy 239:948-956, 2019, doi:10.1016/j.apenergy.2019.01.256.

[7] Seyferth, D., "The Rise and Fall of Tetraethyllead. 2," Organometallics 22(25):5154-5178, 2003, doi:10.1021/om030621b.

[8] Hashimoto, K., "Fuel Ignition Quality Control by Addition and Catalytic Decomposition of Cetane Improver," SAE Technical Paper 2006-01-3361, 2006, doi:10.4271/2006-01-3361.

[9] Kaddatz, J., Andrie, M., Reitz, R.D., and Kokjohn, S., "LightDuty Reactivity Controlled Compression Ignition Combustion 
Using a Cetane Improver," SAE Technical Paper 2012-011110, 2012, doi:10.4271/2012-01-1110.

[10] Dempsey, A.B., Walker, N.R., and Reitz, R.D., "Effect of Cetane Improvers on Gasoline, Ethanol, and Methanol Reactivity and the Implications for RCCI Combustion," SAE Int. J. Fuels Lubr. 6:170-187, 2013.

[11] Ghosh, P., "Predicting the Effect of Cetane Improvers on Diesel Fuels," Energy Fuels 22(2):1073-1079, 2008, doi:10.1021/ef0701079.

[12] Hartmann, M., Tian, K., Hofrath, C., Fikri, M. et al., "Experiments and modeling of ignition delay times, flame structure and intermediate species of EHN-doped stoichiometric n-heptane/air combustion," Proceedings of the Combustion Institute 32(1):197-204, 2009, doi:10.1016/j.proci.2008.06.068.

[13] Goldsborough, S.S., Johnson, M.V., Banyon, C., Pitz, W.J. et al., "Experimental and modeling study of fuel interactions with an alkyl nitrate cetane enhancer, 2-ethyl-hexyl nitrate," Proceedings of the Combustion Institute 35(1):571-579, 2015, doi:10.1016/j.proci.2014.06.048.

[14] Pritchard, H.O., "Thermal decomposition of isooctyl nitrate," Combustion and Flame 75(3-4):415-416, 1989, doi:10.1016/0010-2180(89)90052-7.

[15] Pochet, M., Dias, V., Moreau, B., Foucher, F. et al., "Experimental and numerical study, under LTC conditions, of ammonia ignition delay with and without hydrogen addition," Proceedings of the Combustion Institute, 2018, doi:10.1016/j.proci.2018.05.138.

[16] Mehl, M., Pitz, W.J., Westbrook, C.K., and Curran, H.J., "Kinetic modeling of gasoline surrogate components and mixtures under engine conditions," Proceedings of the Combustion Institute 33(1):193-200, 2011, doi:10.1016/j.proci.2010.05.027.

[17] Yuan, W., Li, Y., Dagaut, P., Yang, J. et al., "Investigation on the pyrolysis and oxidation of toluene over a wide range conditions. II. A comprehensive kinetic modeling study," Combustion and Flame 162(1):22-40, 2015, doi:10.1016/j.combustflame.2014.07.011.

[18] Oleinikov, A.D., Azyazov, V.N., and Mebel, A.M., "Oxidation of cyclopentadienyl radical with molecular oxygen: A theoretical study," Combustion and Flame 191:309-319, 2018, doi:10.1016/j.combustflame.2018.01.010.

[19] Ghildina, A.R., Oleinikov, A.D., Azyazov, V.N., and Mebel, A.M., "Reaction mechanism, rate constants, and product yields for unimolecular and $\mathrm{H}$-assisted decomposition of 2,4cyclopentadienone and oxidation of cyclopentadienyl with atomic oxygen," Combustion and Flame 183:181-193, 2017, doi:10.1016/j.combustflame.2017.05.015.

[20] Galimova, G.R., Azyazov, V.N., and Mebel, A.M., "Reaction mechanism, rate constants, and product yields for the oxidation of Cyclopentadienyl and embedded five-member ring radicals with hydroxyl," Combustion and Flame 187:147-164, 2018, doi:10.1016/j.combustflame.2017.09.005.

[21] Bornemann, H., Scheidt, F., and Sander, W., "Thermal decomposition of 2-ethylhexyl nitrate (2-EHN)," Int. J. Chem. Kinet. 34(1):34-38, 2002, doi:10.1002/kin.10017.

[22] Glarborg, P., Miller, J.A., Ruscic, B., and Klippenstein, S.J., "Modeling nitrogen chemistry in combustion," Progress in Energy and Combustion Science 67:31-68, 2018, doi:10.1016/j.pecs.2018.01.002.

[23] Zhang, K., Glarborg, P., Zhou, X., Zhang, L. et al., "Experimental and Kinetic Modeling Study of Nitroethane Pyrolysis at a Low Pressure: Competition Reactions in the Primary Decomposition," Energy Fuels 30(9):7738-7745, 2016, doi:10.1021/acs.energyfuels.6b01348.

[24] Anderlohr, J.M., Bounaceur, R., Pires Da Cruz, A., and BattinLeclerc, F., "Modeling of autoignition and NO sensitization for the oxidation of IC engine surrogate fuels," Combustion and
Flame 156(2):505-521, 2009, doi:10.1016/i.combustflame.2008.09.009.

[25] Chai, J. and Goldsmith, C.F., "Rate coefficients for fuel + NO 2: Predictive kinetics for HONO and HNO 2 formation," Proceedings of the Combustion Institute 36(1):617-626, 2017, doi:10.1016/j.proci.2016.06.133.

[26] Glänzer, K. and Troe, J., "Thermische Zerfallsreaktionen von Nitroverbindungen in Stosswellen. III: Dissoziation von 1Nitropropan und 2-Nitropropan," HCA 56(5):1691-1698, 1973, doi: $10.1002 /$ hlca. 19730560526.

[27] Rasmussen, C.L., Rasmussen, A.E., and Glarborg, P., "Sensitizing effects of NOx on CH4 oxidation at high pressure," Combustion and Flame 154(3):529-545, 2008, doi:10.1016/j.combustflame.2008.01.012.

[28] Dagaut, P., Lecomte, F., Chevailler, S., and Cathonnet, M., "Mutual Sensitization of the Oxidation of Nitric Oxide and Simple Fuels Over an Extended Temperature Range: Experimental and Detailed Kinetic Modeling," Combustion Science and Technology 148(1-6):27-57, 1999, doi:10.1080/00102209908935771.

[29] Nelson, P.F. and Haynes, B.S., "Hydrocarbon-NOx interactions at low temperatures-1.Conversion of $\mathrm{NO}$ to $\mathrm{NO} 2$ promoted by propane and the formation of HNCO," Symposium (International) on Combustion 25:1003-1010, 1994, doi:10.1016/S0082-0784(06)80737-X.

[30] Dubreuil, A., Foucher, F., Mounaı"m-Rousselle, C., Dayma, G. et al., "HCCI combustion: Effect of NO in EGR," Proceedings of the Combustion Institute 31(2):2879-2886, 2007, doi:10.1016/j.proci.2006.07.168.

[31] Moréac, G., Dagaut, P., Roesler, J.F., and Cathonnet, M., "Nitric oxide interactions with hydrocarbon oxidation in a jetstirred reactor at 10 atm," Combustion and Flame 145(3):512520, 2006, doi:10.1016/j.combustflame.2006.01.002.

[32] Reaction Design, CHEMKIN-PRO (18.2), San Diego, 2017.

[33] Mittal, G., Raju, M.P., and Sung, C.-J., "CFD modeling of twostage ignition in a rapid compression machine: Assessment of zero-dimensional approach," Combustion and Flame 157(7):1316-1324, 2010, doi:10.1016/j.combustflame.2010.02.019.

[34] Zhang, Y., Somers, K.P., Mehl, M., Pitz, W.J. et al., "Probing the antagonistic effect of toluene as a component in surrogate fuel models at low temperatures and high pressures. A case study of toluene/dimethyl ether mixtures," Proceedings of the Combustion Institute 36(1):413-421, 2017, doi:10.1016/j.proci.2016.06.190.

[35] Badra, J.A., Bokhumseen, N., Mulla, N., Sarathy, S.M. et al., "A methodology to relate octane numbers of binary and ternary n-heptane, iso-octane and toluene mixtures with simulated ignition delay times," Fuel 160:458-469, 2015, doi:10.1016/j.fuel.2015.08.007.

[36] Bogin, G.E., Osecky, E., Ratcliff, M.A., Luecke, J. et al., "Ignition Quality Tester (IQT) Investigation of the Negative Temperature Coefficient Region of Alkane Autoignition," Energy \& fuels : an American Chemical Society journal 27(3):1632-1642, 2013, doi:10.1021/ef301738b.

\section{Contact Information}

$\underline{\text { mickael.matrat@ifpen.fr }}$

\section{Definitions/Abbreviations}

IC Internal combustion

Page 7 of 8 
GCI

$\mathbf{T}$

$\Phi$

$\mathrm{NO}_{\mathrm{x}}$

EHN

EHO

IQT

CN

RON

RCM

IDT

CFR
Gasoline compression

ignition

Temperature

Equivalence ratio

Nitrogen oxides

2-Ethylhexyl nitrate

2-Ethylhexyloxy

Ignition quality test

Cetane number

Research octane number

Rapid compression machine

Ignition delay time

Cooperative Fuels Research 